\title{
Sentimentos dos filhos ao vivenciarem o adoecimento dos pais
}

\author{
Julia Wakiuchi ${ }^{1}$, Aline Lima Ribeiro ${ }^{2}$, Gabriella Michel dos Santos Benedetti ${ }^{3}$, \\ Maria de Fátima Garcia Lopes Merino ${ }^{4}$, Sonia Silva Marcon ${ }^{5}$, Catarina Aparecida Sales ${ }^{6}$
}

\footnotetext{
${ }^{1}$ Enfermeira, Mestre em Enfermagem. Discente do Programa de Pós-Graduação em Enfermagem, nível Doutorado, da Universidade Estadual de Maringá.

Maringá, PR, Brasil. E-mail:

julia.wakiuchi@gmail.com.

${ }^{2}$ Enfermeira. Maringá, PR, Brasil. E-mail: aline Ir@hotmail.com.

${ }^{3}$ Enfermeira, Mestre em Enfermagem. Discente do Programa de Pós-Graduação em Enfermagem, nível Doutorado, da Universidade Estadual de Maringá. Docente da Universidade Estadual do Paraná. Paranavaí, PR, Brasil. E-mail: enfermeiragabi@hotmail.com.

${ }^{4}$ Enfermeira, Mestre em Enfermagem. Discente do Programa de Pós-Graduação em Enfermagem, nível Doutorado, da Universidade Estadual de Maringá. Professora Assistente da Universidade Estadual de Maringá. Maringá, PR, Brasil. Email: fatimamerino@gmail.com.

${ }^{5}$ Enfermeira, Doutora em Enfermagem. Professora Titular da Universidade Estadual de Maringá. Maringá, PR, Brasil. E-mail: soniasilva.marcon@gmail.com.
}

${ }^{6}$ Enfermeira, Doutora em Enfermagem na Saúde do Adulto. Professora Adjunto da Universidade Estadual de Maringá. Maringá, PR, Brasil. E-mail: casales@uem.br.

Recebido: 30/05/2016

Aceito: 29/09/2016.

Publicado: 22/12/2016.

Como citar esse artigo:

Wakiuchi J, Ribeiro AL, Benedetti GMS, Merino MFGL, Marcon SS, Sales CA. Sentimentos dos filhos ao vivenciarem o adoecimento dos pais. Rev. Eletr. Enf. [Internet]. 2016 [acesso em: ____18:e1203. Disponível em: http://dx.doi.org/10.5216/ree.v18.41543.

\section{RESUMO}

Objetivou-se apreender as vivências de crianças que experienciam o adoecimento de seus pais por câncer. Estudo descritivo de abordagem qualitativa, com seis crianças entre 10 e 12 anos incompletos de idade, filhos de pacientes com câncer atendidos por uma instituição de apoio. Os dados foram coletados entre julho e agosto de 2015, a partir da questão norteadora: "Como você se sente com a doença do seu pai/mãe?". Da análise emergiram duas categorias: Reconhecendo a doença e a possibilidade da morte dos pais e, Crescendo como criança e vivendo como adulto: as repercussões do câncer dos pais na vida dos filhos, que revelam que as crianças compreendem o câncer e a possibilidade da morte de seus pais, sendo também afetados pela doença que adentra seu lar. Conclui-se que, vivenciando os temores e repercussões do câncer, as crianças devem ser acompanhadas pela família e equipe de saúde durante o adoecimento dos pais.

Descritores: Neoplasias; Criança; Poder Familiar; Enfermagem Pediátrica; Pesquisa Qualitativa.

\section{INTRODUÇÃO}

O adoecimento por câncer tem se tornado cada vez mais presente nas famílias em todo o mundo, o que pode ser explicado pela crescente agressividade da doença, que hoje é considerada a segunda causa de morte no Brasil $^{(1)}$, além das estimativas alarmantes, que calculam um total de 596.000 casos novos de câncer no Brasil entre 2016 e $2017^{(2)}$.

Ademais, o desenvolvimento de tecnologias ampliadas para 
diagnosticar e aperfeiçoar os meios de tratamento ${ }^{(3)}$, permitem o diagnóstico precoce e aumento da sobrevida. Isto repercute diretamente no crescente número de casos de neoplasias na atualidade. Nesse sentido, as doenças são diagnosticadas precocemente, observando-se o adoecimento de pessoas cada vez mais jovens e, em idade reprodutiva. Diante desse cenário, a literatura aponta para a seguinte problemática: o adoecimento de pais de crianças que ainda vivenciam a infância e a idade escolar, necessitando de cuidados $^{(4)}$.

Quando pai ou mãe são diagnosticados com um câncer, seu papel parental pode ser afetado, modificando as rotinas de cuidado com os filhos, capacidade de zelo e, consequentemente, desestruturando o $\mid \operatorname{lar}^{(5)}$. Desse modo, a repercussão do câncer na vida das crianças é extremamente impactante, visto que estas são diretamente afetadas pelo agravamento da saúde de seus pais. Embora crianças e adolescentes demonstrem boa aceitação do adoecimento dos pais, um estudo realizado com filhos de mães com câncer demonstrou que os mesmos podem desenvolver problemas emocionais importantes, principalmente quando os pais apresentam alto nível de ansiedade e não dialogam sobre a doença com seus filhos ${ }^{(6)}$.

Vale ressaltar que, muitas vezes, a família prefere proteger a criança de preocupações com os problemas cotidianos, esquecendo-se que ela recebe informações constantemente diante de sua interação com o mundo e que, de acordo com seu nível cognitivo, ela é capaz de criar representações do que acontece ao seu redor ${ }^{(7)}$. Nesse sentido, o temor dos pais em revelar o real diagnóstico aos seus filhos se deve a um desejo de protegê-los do sofrimento, pois acreditam que seus filhos possam passar pelos mesmos medos por eles enfrentados, levando-os a transmitir parcialmente as informações ${ }^{(8)}$.

No entanto, um estudo realizado na Arábia Saudita com crianças e adolescentes entre cinco e 16 anos, filhos de mães com câncer de mama, demonstrou que discutir o diagnóstico do câncer com a criança melhorou a forma de como esta trata sua mãe, assim como tem efeitos positivos na personalidade da criança como um todo ${ }^{(4)}$. Ademais, a existência de um diálogo honesto e gradual entre pais e filhos estabelece uma relação de confiança entre os mesmos, o que possibilita resultados positivos para autoconfiança das crianças no futuro ${ }^{(8)}$.

Ante tais considerações, questiona-se: como se sentem as crianças que vivenciam o adoecimento de seus pais por câncer? Uma vez que explorar os sentimentos e conhecimentos da criança sobre uma neoplasia, pode ser fundamental para os profissionais de saúde, conferindo subsídios para o cuidado de pais que assistem seus filhos durante o adoecimento. A instituição familiar, como primeira referência de uma pessoa em sua vida e principal fonte de apoio nos momentos de doença, deve ser foco de atenção da equipe de saúde, que tem o compromisso de auxiliar todos seus membros a lidarem com os conflitos inerentes ao adoecimento no $\operatorname{lar}\left({ }^{(9)}\right.$.

Mais ainda, as crianças devem estar preparadas para seu futuro, organizando seus sentimentos a fim de compreender como elas percebem o câncer de seus pais. Pauta-se, portanto, como objetivo deste estudo apreender as vivências de crianças que experienciam o adoecimento de seus pais por câncer. 


\section{MÉTODO}

Estudo de abordagem qualitativa, que possibilita o desvelamento de subjetividades, significados, valores e atitudes das vivências do ser humano, enfocando o indivíduo e a sociedade de maneira profunda e não quantificável ${ }^{(10)}$.

Participaram deste estudo seis crianças, filhos de pai ou mãe com diagnóstico de câncer, atendidos por uma instituição filantrópica de apoio, localizada no Noroeste do Paraná, Brasil. As crianças foram localizadas a partir do cadastro da família na referida instituição de apoio, a partir dos seguintes critérios de inclusão: possuir entre 10 e 12 anos incompletos, caracterizada como criança segundo o Estatuto da Criança e do Adolescente ${ }^{(11)}$, ter pai ou mãe realizando tratamento ativo contra o câncer por no mínimo seis meses, serem residentes na cidade sede da instituição, e que tenham ciência do adoecimento dos pais. 0 cumprimento do último critério foi verificado junto aos pais das crianças, antes de qualquer contato com os filhos. Quanto aos critérios de exclusão, considerou-se o endereço incompleto para a localização da família, ou a morte do pai ou mãe da criança.

A partir da busca de cadastros de famílias na instituição, foram encontradas 24 crianças na faixa etária estabelecida, dentre os quais foi possível o contato telefônico de apenas 15 famílias. Neste momento, foram explanados os objetivos da pesquisa e verificação da ciência da doença por parte da criança, sendo excluídas duas famílias, que não haviam revelado aos filhos o adoecimento por câncer. Dentre as 13 famílias restantes, houve recusa de sete pais, sendo realizadas seis entrevistas, com duração média de 30 minutos cada.

As entrevistas aconteceram no domicílio das famílias, sendo que, para criação de vínculo com as crianças foram necessários de três a quatro encontros com as famílias, até que os filhos se sentissem confortáveis em permanecer a sós com a pesquisadora e, contassem suas vivências e sentimentos tranquilamente. Além disso, foi solicitado aos pais que se retirassem no momento das entrevistas, para que as crianças tivessem mais liberdade ao expor seus sentimentos mais íntimos, muitas vezes não revelados aos pais. A coleta de dados ocorreu entre os meses de agosto e outubro de 2015 , a partir da questão norteadora: “Como você se sente com a doença do seu pai/mãe?". A fim de dar continuidade e aprofundamento no relato das crianças, foram utilizadas questões de apoio como "Explique-me melhor sobre...", "Conte-me mais sobre...".

As entrevistas foram registradas em gravador digital e, posteriormente, transcritas na íntegra. A análise de dados foi guiada pelos passos da Análise de Conteúdo Temática ${ }^{(10)}$, que se constituem em: préanálise, exploração do material e tratamento dos resultados, inferência e interpretação. Da análise, emergiram duas categorias temáticas, intituladas - Reconhecendo a doença e a possibilidade da morte dos pais e, - Crescendo como criança e vivendo como adulto: as repercussões do câncer dos pais na vida dos filhos, que foram discutidas a partir da literatura atual sobre o tema.

Como se trata de uma pesquisa que envolve seres humanos, foram observados os aspectos éticos disciplinados pela Resolução no 466/2012 do Conselho Nacional de Saúde, com aprovação pelo Comitê Permanente de Ética em Pesquisas com Seres Humanos da Universidade Estadual de Maringá (COPEP UEM), 
mediante o Parecer no 1.166.696, de 13/04/2015. O Termo de Consentimento Livre e Esclarecido (TCLE) para participantes menores de 18 anos foi assinado pelos pais das crianças em duas vias. As crianças, por sua vez, registraram seu assentimento em participar da pesquisa, assinando no espaço específico no próprio TCLE já assinado por seus responsáveis.

O anonimato das crianças foi preservado por meio da utilização de códigos de identificação (C1, C2, C3, ..., C6), seguidos pelas respectivas idades.

\section{RESULTADOS E DISCUSSÃO}

Compuseram os resultados deste estudo os discursos de seis crianças que vivenciam o câncer de seus pais em seus lares. Destes, quatro eram do sexo masculino e duas do feminino, com idades entre 10 e 12 anos de idade incompletos. Dentre os pais, cinco eram mães e apenas um era pai. A localização do câncer dos pais variou entre garganta, tireoide e mama, sendo que o mais predominante foi o de mama, com quatro casos. A análise emergiu em duas categorias, apresentadas a seguir.

\section{Reconhecendo a doença e a possibilidade da morte dos pais}

Ao conviver com o câncer no lar, todos os familiares se envolvem intimamente com a nova rotina estabelecida pela doença, que gera sentimentos inusitados pelo novo desafio que se impõe e, ocasiona exaustão física e psíquica para com os envolvidos com o tratamento ${ }^{(12)}$. De igual modo, as crianças que vivenciam o câncer na família também percebem o adoecimento de seus pais e convivem com as repercussões que sua veemência causa no ambiente familiar, arquitetando suas ideias e entendimento sobre o câncer e suas repercussões.

Neste estudo, o reconhecimento do câncer dos pais pelas crianças, de modo geral, partiu de concepções prévias, adaptadas ao que puderam visualizar fisicamente nos mesmos. As crianças demonstram que as concepções que possuem sobre o câncer são oriundas de conhecimentos que adquiriram através de seus familiares, em sua casa ou então que buscaram saber por meios de informações que estão ao seu alcance, como mostram os discursos:

[...] Câncer é uma bactéria que tem por dentro? Eu acho que câncer é uma bactéria que tem por dentro, que daí ela faz cair o cabelo, daí ela come aqui (bochecha), por que meu pai estava assim. (C6, 11 anos)

[...] Não sabia o que era o câncer. Faz um pouco de tempo que eu já fiquei sabendo, pela televisão, informação assim. (C1, 11 anos)

[...] Tem vários cânceres, câncer de pele, câncer de pelo... Não sei muito não. Eu vejo passar na TV. (C2, 10 anos)

Foi possível perceber que as informações chegam para as crianças, independente da vontade de seus familiares, pois elas próprias buscam o entendimento, criam suas acepções por meios próprios, mesmo que inocentemente relatados. Tal construção é reflexo da capacidade de aquisição de conhecimento da criança, que interage com o mundo e cria suas percepções ${ }^{(7)}$.

Além disso, os processos adaptativos desenvolvidos pelas crianças são particulares a sua faixa etária, 
de forma que elas reagem diferentemente às adversidades impostas pelo cotidiano ${ }^{(13)}$. Assim, apesar da candura envolvida em seu pensar, elas demonstram ter ciência da gravidade da doença e compreensão sobre as consequências que ela acarreta.

Por meio das narrativas pode-se notar que a revelação da doença dos pais foi percebida através de sinais físicos que se manifestaram no decorrer da doença. Evidenciou-se que a queda do cabelo foi a repercussão física mais estigmatizada, principalmente quando se tratava das mães, sendo assim marcante na trajetória da evolução da doença para as crianças, como elas mesmo as retratam:

[...] Ah foi triste. Porque no começo, quando ela descobriu que teve a doença, achou que não era nada. Achou que era normal. Só que daí fez os exames, foi descobrindo mais, até que ela perdeu o cabelo, ficou careca, aí foi dolorido! Ver minha mãe careca. (C5, 11 anos)

[...] Eu tinha medo porque teve uma época que o cabelo dela começou a cair. Daí eu vi que ela estava com câncer. (C2, 10 anos)

[...] Quando perdeu o cabelo também, ela já avisou antes, se ela não tivesse avisado e tivesse caído eu não ia me sentir muito bem [...]. Se ela não tivesse falado que ia cair o cabelo dela aí a gente ia achar que ela ia morrer, por que o cabelo começou a cair, aí ia ter que arrancar o seio. (C3, 11 anos)

A perda dos cabelos por uma mulher tem repercussões em sua autoidentidade, pois simboliza a atratividade sexual, identidade cultural e saúde física, sendo estigmatizante e significativa tanto as mesmas, como para quem as rodeia ${ }^{(14)}$. Seguindo este pensar, a queda do cabelo é um momento de incertezas que vem acompanhado de dor, medo e angústias. Esse fato, para as crianças é a confirmação de que seus pais estão realmente doentes, é quando elas percebem a fraqueza e as repercussões que a doença pode causar.

Além disso, as falas demonstram que, a compreensão do câncer também é interligada a possibilidade da morte. Ao contrário dos rodeios realizados pelos adultos, as crianças verbalizam a morte como atrelada a doença e, não hesitam ao falar sobre ela:

[...] É uma doença que mata, que é muito ruim, não sei quantos por cento de cura, de chance que a pessoa tem de sobreviver. (C1, 11 anos)

[...] Porque eu acho que a maioria das pessoas com câncer morre, acaba morrendo. Fui ver lá na internet, uma pessoa tinha morrido de câncer. Também meu amigo falou que o avô dele morreu de câncer. (C4, 10 anos)

[...] Porque ela podia morrer por causa desse negocio, porque já tem mulheres que já morreram por causa de um câncer, sei por que eu vi e minha mãe falou para mim e ela me chamou para ver a reportagem e eu já vi. (C3, 11 anos)

Na nossa sociedade nos deparamos com uma relutância em reconhecer a morte e, consequentemente, em se falar sobre ela ${ }^{(15)}$. As crianças, ao revelarem a consciência da possibilidade da morte, encontram-na atrelada às vivências daqueles que já passaram por essa jornada e, de maneira ainda pura, revelam o medo de perder os pais, mesmo sem afirmar que a morte chegaria até eles.

Haja vista, o câncer ainda possui o estigma social negativista de sentença de morte, de ameaça à vida 
social e, do pensamento de que a partir do diagnóstico a vida se volta totalmente ao adoecer ${ }^{(16)}$. Além disso, doente e família ficam expostos a uma tormenta que os atingem principalmente no âmbito emocional, sendo evidente sua sobrecarga nos momentos mais impactantes da doença, como o diagnóstico ${ }^{(17)}$. Tais experiências e repercussões pelas crianças serão exploradas na próxima categoria.

Crescendo como criança e vivendo como adulto: as repercussões do câncer dos pais na vida dos filhos

O câncer na família gera a necessidade de cuidados específicos e diferenciados para com o doente, o que envolve muitas vezes a abdicação de planos, de desejos em contraste com a necessidade de dedicação ímpar ao paciente e suas necessidades ${ }^{(12)}$. Pode-se afirmar assim, que o câncer na família atinge não só o doente, mas também afeta fundamentalmente todos os seus membros.

No decorrer da doença, os tratamentos contra o câncer vão ficando mais complexos e os pais não conseguem esconder os momentos de angústia e sofrimento de seus filhos. De tal forma, as crianças são afetadas potencialmente pelo desequilíbrio no lar, percebendo as repercussões e sentimentos que um cotidiano de doença impôs em suas vidas:

[...] No colégio as notas foram abaixando por causa disso. No segundo ano, foram abaixando as notas. Porque daí eu meu sentia triste por ver minha mãe assim. Perdi aquela vontade de estudar, aí foi abaixando as notas. (C5, 11 anos)

[...] Porque se tiver a mãe doente, que criança que vai ficar feliz? Vai estudar tranquila? Fazer estudo? (C1, 11 anos) [...] Eu ficava um pouco triste de ver meu pai lá tendo que fazer quimio e essas coisas, porque eu via ele antes e, hoje não é a mesma coisa. Eu vejo ele assim, doente e tudo, e antes ele estava feliz. (C6, 11 anos)

As crianças explicitam em seus discursos que, seu bem estar é diretamente relacionado com o bem estar dos pais e, por mais que os mesmos tentem esconder suas angústias, os filhos as percebem e tomam para si parte desse sofrimento. Atingidos por essa transformação em suas vidas, as crianças são afetadas e não conseguem executar suas atividades cotidianas como anteriormente. A vivência da doença leva a grandes e diversificados conflitos emocionais, sendo permeada por momentos de ansiedade extrema ${ }^{(18)}$. Tal conjuntura carrega consigo uma carga de sofrimentos e expectativas das mais variadas para todos os envolvidos ${ }^{(19)}$.

Por conseguinte, as vivências pelas quais a criança passa ao conviver com o câncer no lar são fortes e efusivas, de maneira que as marcas profundas deixadas pela doença as fazem modificar seu comportamento e aproximar-se de seus pais, pois entendem que a sua presença e seus cuidados são imprescindíveis nesse momento, como demonstrado a seguir:

[...] Mudei... Bastante, no comportamento e de ficar em casa, por causa da minha mãe. Por causa da minha mãe, porque se ela estivesse deitada e ela precisasse de alguma coisa, eu estaria perto para ajudar ela [...]. Antes eu saía de manhã, aí eu voltava pra ir correndo para ir pra escola, chegava da escola já ia para rua de novo. Aí dia de sábado e domingo eu saía de manhã voltava só à noite. Agora já não, eu chego da escola já fico dentro de casa, eu não saio. (C3, 11 anos) 
[...] Eu parei de ficar indo na rua, parei de ficar fazendo bagunça na escola, porque se eu fizesse bagunça, minha mãe não poderia ir lá na escola (C2, 10 anos)

Diante das falas, conseguimos perceber que as crianças sentem a necessidade do cuidado de seus pais e, ao mesmo tempo, percebem-se como responsáveis pelos mesmos, mediante a necessidade de sua ajuda - invertem-se os papéis, sendo o filho agora provedor de cuidados. Apesar de não ser necessário, e em muitos casos não ser ao menos proferida essa necessidade, as crianças encaram isso como um papel designado a elas e, se mostram orgulhosas de suas atitudes, agindo com naturalidade. Essas atitudes também são encontradas em um estudo realizado na Arábia Saudita, que reforçam essa tendência da criança de aproximação e preocupação com os pais quando estes enfrentam o câncer ${ }^{(4)}$.

No discurso emocionante de uma das crianças observamos que o mesmo além de modificar suas atitudes cotidianas em prol dos pais, demonstra carinho e amor pelos mesmos, expressando através de suas palavras sua tristeza frente à possibilidade da morte, pensando quanto seria penosa suas vidas sem eles.

[...] comecei a obedecer mais, a abraçar mais, a beijar mais. Porque se você perde sua mãe, como você vai ficar? Você vai ficar metade, dividido. Tipo, se ela for, leva o coração meio junto. Aí fica ruim... (O garoto fica com a voz embargada, em silêncio). (C1, 11 anos)

A benevolência, permeada pelo amor para com o outro é a possibilidade extrema de se relacionar com uma pessoa e executar um cuidado verdadeiro, no qual se deixa o mundo de lado, para se reconduzir a este patamar ${ }^{(20)}$. Apesar de todos os percalços enfrentados, o câncer transformou a vida dessas crianças e, os fortaleceram, fazendo com que eles desenvolvessem um novo olhar sobre si e sobre seus vínculos. A partir do adoecimento do pai ou mãe, essas crianças aprenderam uma nova forma de ser e de relacionar, agregando valor à saúde e a união na família, além de reconhecerem a importância e o amor singular que se expressa entre pais e filhos.

\section{CONCLUSÃO}

Os resultados do presente estudo demonstram que, as crianças possuem mecanismos próprios de construir a própria realidade, demonstrando ter compreensão sobre o câncer de seus pais, além da possibilidade da morte, que se revela como iminência do agravamento da doença. A compreensão acerca do adoecimento dos pais mobiliza as crianças ao cuidado, o que transforma suas vidas em prol do zelo, carinho e responsabilidade, que florescem em meio a inocência de ser criança e os encargos próprios da vida adulta.

Notamos que a vivência do câncer no seio familiar possibilita a unificação da família, desenvolve novos olhares em seus integrantes, direcionando-os a perceber a vida de outra maneira. Foi possível observar que as crianças possuem uma força própria e, apesar de pouca experiência e pouco conhecimento elas reagem de forma firme aos obstáculos, e enfrentam as dificuldades de forma exemplar. Elas mostraram que, apesar da pouca idade possuem princípios e coragem, o que é contrário à imagem frágil que a sociedade tem sobre elas, ou seja, o fato de experenciarem o adoecimento e suas repercussões de maneira extrema e tão próxima 
as levam a amadurecer precocemente.

Apesar de poucos estudos explorarem tal vertente de atenção, é possível afirmar que as famílias e, principalmente as crianças, necessitam de assistência durante o adoecimento dos pais, visando assim ações direcionadas ao desenvolvimento sadio desses seres. A enfermagem, em especial, por estar na linha de frente do cuidado junto ao paciente e a família, deve estar preparada para amparar tais crianças, que demonstram a necessidade de atenção individual e holística para suas dúvidas, medos e anseios.

O presente estudo vem contribuir para melhor compreensão das vivências de crianças que experienciam o adoecimento de seus pais por câncer, possibilitando um direcionamento para a equipe de saúde no sentido de como abordar e auxiliar as crianças e suas famílias. Ressalta-se, portanto, a necessidade de novos estudos qualitativos nessa área para aprofundar e ampliar o conhecimento sobre o assunto.

\section{REFERÊNCIAS}

1. DATASUS [Internet]. Brasília: Ministério da Saúde; 2016 [acesso em: 14 abr 2016]. Disponível em:

http://tabnet.datasus.gov.br/cgi/tabcgi.exe?sim/cnv/pobt10uf.def

2. Ministério da Saúde. Instituto Nacional de Câncer José Alencar Gomes da Silva.

Estimativa 2016: incidência de câncer no Brasil [Internet]. 2016 [acesso em: 09 ago 2016]. Disponível em:

http://www.inca.gov.br/estimativa/2016/estimativa-2016-v11.pdf

3. Silva RCV, Cruz EA. Planejamento da assistência de enfermagem ao paciente com câncer: reflexão teórica sobre as dimensões sociais. Esc. Anna Nery Rev. Enferm. 2011;15(1):180-5.

4. Al-Zaben F, Al-Amoudi SM, El-deek BS, Koenig HG. Impact of maternal breast cancer on school-aged children in Saudi Arabia. BMC res. notes. 2014;261(7):1-5.

5. Mazzotti E, Serranò F, Sebastiani C, Marchetti P. Mother-child relationship as perceived by breast cancer women. Psych. 2012;3(12):1027-34.

6. Huizinga GA, Visser A, Van der Graaf WT, Hoekstra HJ, Stewart RE, Hoekstra-Weebers JE. Family-oriented multilevel study on the psychological functioning of adolescent children having a mother with cancer. Psycho-oncol.

2011;20(7):730-7.

7. Luchesi BM, Dupas G, Monteiro LC, Marques S, Pavarini SC. Sentimentos e atitudes de crianças em relação aos maus tratos a pessoas idosas. Rev. Eletr. Enf. [Internet].; 2013 [acesso em: 10 jun 2015];15(3):619-27. Disponível em: https://www.fen.ufg.br/fen_revista/v15/n3/pdf/v15n3a03.pdf

8. Morera AR. ¿Cómo explican los niños y adolescentes el cáncer avanzado o terminal de sus padres?. Psicooncología (Pozuelo de Alarcón). 2015;12(1):171-82.

9. Santos QN. Estratégia de enfrentamento (coping) da família ante um membro familiar hospitalizado: uma revisão de literatura brasileira. Mudanças. 2013;21(2):40-7.

10. Minayo MCS. O desafio do conhecimento: pesquisa qualitativa em saúde. 13th ed. São Paulo: Hucitec; 2010. 11. Lei № 8.069, de 13 de julho de 1990 (BR) [Internet]. Dispõe sobre o Estatuto da Criança e do Adolescente e dá outras providências. Presidência da República. Casa Civil. Subchefia para assuntos jurídicos. Texto compilado. 13 de julho de 1990 [acesso em: 11 ago 2016]. Disponível em: https://www.planalto.gov.br/ccivil_03/leis/l8069.htm.

12. Benedetti GMS, Wakiuchi J, Costa JR, Prado E, Sampaio JN, Sales CA. Sobrecarga emocional dos familiares de pacientes com câncer: ambiguidade de sentimentos ao cuidar. Ciênc. cuid. saúde. 2015;14(3):1220-8.

13. Ribeiro EAS, Souza EA. A complexidade da Morte: a morte e seu significado diante da compreensão humana. Como educar para compreendê-la melhor? Revista Eventos Pedagógicos. 2011;2(2):76-83.

14. Coe K, Staten L, Rosales C, Swanson M. The enigma of the stigma of hair loss: why is cancer-treatment related alopecia so traumatic for women? The Open Cancer Journal. 2013;6:1-8.

15. Phillips J. What will it take to put talking about death on our agenda? Collegian. 2013;20(4):205-6.

16. Tang PL, Mayer DK, Chou FH. The experience of cancer stigma in Taiwan: a qualitative study of female cancer

Rev. Eletr. Enf. [Internet]. 2016 [acesso em:_____];18:e1203. Disponível em: http://dx.doi.org/10.5216/ree.v18.41543. 
patients. Arch. psychiatr. nurs. 2016;30(2):204-9.

17. Northouse LL, Katapodi MC, Schafenacker AM, Weiss D. The Impact of Caregiving on the Psychological well-being of family caregivers and cancer patients. Semin. oncol. nurs. 2012;28(4):236-45.

18. Trill MD. Anxiety and sleep disorders in cancer patients. EJC Suppl. 2013;11(2):216-224.

19. Visoná F, Prevedello M, Souza EN. Câncer na família: percepções de familiares. Rev. enferm. UFSM. 2012;2(1):14555.

20. Fernandes MA. O cuidado como amor em Heidegger. Rev. abordagem gestál. 2011; 17(2):158-71. 